\title{
Features of auroral breakup obtained using data of ground-based television observations: case study
}

\author{
E. E. Antonova ${ }^{1,3}$, I. A. Kornilov ${ }^{2}$, T. A. Kornilova ${ }^{2}$, O. I. Kornilov ${ }^{2}$, and M. V. Stepanova ${ }^{4}$ \\ ${ }^{1}$ Skobeltsyn Institute of Nuclear Physics Moscow State University, Moscow, Russia \\ ${ }^{2}$ Polar Geophysical Institute KSC RAS, Apatity, Russia \\ ${ }^{3}$ Space Research Institute RAS, Moscow, Russia \\ ${ }^{4}$ Physics Department, Universidad de Santiago de Chile, Santiago, Chile
}

Received: 8 September 2008 - Revised: 27 February 2009 - Accepted: 27 February 2009 - Published: 1 April 2009

\begin{abstract}
The knowledge about the relative timing of events during the substorm expansion phase onset is very important for understanding the physics of substorms. In this work ground-based television (TV) imaging technique was used for observations of the first auroral arc brightening near zenith of TV chamber for the case of an isolated substorm. The method of the TV image filtration was used giving the possibility to analyze motion of sub visual auroral arcs. The analysis of the connection between the first auroral arc brightening and the beginning of magnetic disturbance was carried out. It was shown that luminosity disturbance is absent to the pole of breakup arc before the breakup and there exist a delay time between the brightening and start of intense magnetic fluctuations in the Pi1-Pi2 frequency ranges. The results obtained have been compared with predictions of theories of auroral breakup.
\end{abstract}

Keywords. Magnetospheric physics (Auroral phenomena; Storms and substorms)

\section{Introduction}

The problem of isolated substorm breakup onset continues to be one of the main unsolved problems of the physics of the magnetosphere. According to the classical scheme of Akasofu (1964), supported by numerous observations (see Lyons et al., 2002) the breakup begins by the brightening of the most equatorial arc drifting equatorward during the substorm growth phase or by formation of a new auroral arc. No consensus exists till now about the origin of instability leading



Correspondence to: E. E. Antonova (antonova@ orearm.msk.ru) to such brightening and location of the region of such instability development. The "outside-in" model suggests the occurrence of magnetic reconnection at a downstream distance of $\sim 15-20 R_{E}$ in the magnetotail. As a result, the earthward moving plasma jet should impinge the magnetic field in the inner magnetosphere and produces the first auroral arc brightening. The "inside-out" model invokes a development of some kind of instability in the region of the magnetosphere mapped on the equatorial boundary of auroral oval. Reconnection in the magnetotail in accordance with "insideout" model appears with one-two minutes delay. Verification of the suggested models meets with definite difficulties if even the data of multisatellite observations are used (see the comprehensive results presented by Lui et al. (2008) for the "inside-out" model and by Angelopoulos et al. (2008) for the "outside-in" model).

The main difficulty of the "outside-in" model is the high level of almost constantly observed turbulence in the plasma sheet (see Angelopoulos et al., 1999; Borovsky et al., 1997; Borovsky and Funsten, 2003; Antonova, 2002), including bursty bulk flows (BBFs). The earthward directed BBF were typical of about $7-15 \%$ of the time of observation for both substorm and quiet periods (Baumjohann et al., 1990; Angelopoulos et al., 1992; Petrukovich et al., 2001). Therefore, the probability to observe reconnection in the magnetotail and directed to the Earth plasma flow before the first auroral arc brightening is comparatively high. BBF were also observed as the auroral streamers (see Sergeev et al., 1999). Therefore, the "outside-in" model needs additional proofs evidencing that produced by plasma jet electromagnetic signal excites the most equatorial auroral arc, which leads to its brightening. On contrary, the verification of the "inside-out" model requires the absence of such signal. Unfortunately the probability to miss signals localized in $\mathrm{Y}$ and

Published by Copernicus Publications on behalf of the European Geosciences Union. 
$\mathrm{Z}$ directions with a scale $<0.5 R_{E}$ exists even in the case of 11 satellite observations presented by Lui et al. (2008).

Relative timing of the beginning of first auroral arc brightening and start of the magnetic disturbance is also very important for the development of adequate model of substorm expansion phase onset. Liou et al. (1999) showed the existence of definite time delay $\sim 1$ min between the beginning of brightening and the appearance of the magnetic field disturbance in Pi2 frequency range. Results of Mende et al. (2007), Angelopoulos et al. (2008) supported this finding. However, Kepko et al. (2004) showed that the onsets of both nightside $\mathrm{Pi} 2$ pulsations and magnetic bay variations were simultaneous with auroral onset.

Under the light of above mentioned difficulties the selection of the proper ground-based observations in vicinity of the first auroral arc brightening is one of the most important aspects for solution of the substorm onset problem (see arguments presented by Lui, 2000). The system including 20 ground-based observatories (GBO-s) was created as a part of THEMIS project to provide near contiguous coverage over North America (Donovan et al., 2006; Mende et al., 2007). The network of imagers took global scale image collages (mosaics) with $3 \mathrm{~s}$ cadence and now gives many interesting results. At the same time, it would be interesting to analyze the substorm expansion phase onset with better resolution order to select some features of auroral breakup of smaller time scales. The television (TV) observations at Lovosero observatory $\left(64.1^{\circ} \mathrm{N}, 115.5 \mathrm{E}, \mathrm{MLT}=\mathrm{UT}+3 \mathrm{~h}\right)$, belonging to the Polar Geophysical Institute, provide the possibility to analyze the auroral breakup fine structure with a time resolution of 25 frames per second and with a high spatial resolution ( $\sim 100 \mathrm{~m}$ in the zenith). Preliminary results of such analysis summarized by Kornilov et al. (2008a, b) demonstrated different pictures of the auroral breakups. It was possible sometimes to select some subvisual precursors of breakup moving from the north (see Kornilova et al., 2004). However, such motions were comparatively slow (Kornilov et al., 2008a).

In this paper, we present the results of the analysis of the event 28 January 2003. The main feature of this event is the possibility to observe an isolated substorm with first brightening arc just near zenith of the Lovosero observatory. We study the main features of the auroral brightening development and try to find the disturbances existing poleward of the brightening arc for the time interval $\sim$ min before the brightening. We also analyze the disturbances of the magnetic field at the observatory and try to determine the time delay between the first auroral arc brightening and the magnetic disturbances onset.

\section{Event study}

Figure 1 shows geomagnetic activity indices provided by the Kyoto data center on 28 January 2003 . The isolated substorm was developed near 20:00 UT with maximal auroral electrojet index AE 400 nT. The value of AE was smaller than $100 \mathrm{nT}$ during $\sim 7 \mathrm{~h}$ before the substorm onset, whereas the $D_{s t}$ index module was $\sim 5 \mathrm{nT}$. Figure 2 shows the $\mathrm{X}$ component of magnetic field at Lovozero for the event 28 January 2003. The amplitude of the disturbance does not exceed $250 \mathrm{nT}$. Figure 3 shows the solar wind parameters taken from the OMNI database. Solar wind dynamic pressure constituted $\sim 4 \mathrm{nPa}$, solar wind velocity was nearly $435 \mathrm{~km} / \mathrm{s}$, IMF $B_{z}$ had southward orientation and was -2 to $-1 \mathrm{nT}$, $B_{y}$ was near to $(-3.5 \mathrm{nT})$. Analysis of the variations of solar wind parameters shows that it is difficult to find the appropriate trigger of expansion phase onset in the solar wind parameters. IMF $B_{z}$ and $B_{y}$ do not change direction, velocity and dynamic pressure are practically stable.

Auroral data were provided by SIT vidicon TV camera with all-sky lens. Computer framegraber videocard and special software allowed digitization of TV frames (up to $720 \times 512$ pixels) and the arbitrary chosen frame fragments. The method used to process TV data is based on the sliding averaging of successive frames in combination with the effective spatial-temporal filtering of these data (Kornilov et al., 2003). The special methods for the television images processing were used to detect fine subvisual structures and to trace the details of motion of fine auroral structures.

Figure 4 shows the series of TV frames as observed at 20:31:50-20:32:25 UT with $1 \mathrm{~s}$ resolution. Prior to the onset, the aurora was relatively stationary with an extended east west arc located relatively near to the zenith of the observatory. Comparatively week diffuse-like luminosity and comparatively bright arc were observed to the north of the prebreakup arc. It can be seen in Fig. 4, that splitting of auroral arc was observed before breakup. It was followed by the appearance of localized brightening at 20:32:05 UT. The first localized brightening was formed as a "hot spot" with approximately the same scale in the east-west and north-south directions. Brightness of this spot continuously increased till 20:32:21 UT for $15 \mathrm{~s}$ interval. Auroral arc with waved structure was observed only after 20:32:21 UT, which is consistent with the previous results by Mende et al. (2007) and Liang et al. (2008). The process was followed later by the breakup arc flash and by the appearance of new bright rayed formations, which propagated poleward.

Figure 5 shows standard and filtered keograms of the analyzed event along with the filtered magnetometer data. Filtered keogram was obtained using gradient filtering method based on the fast Fourier transform technique (see Kornilov et al., 2003). Such method gives the possibility to reveal fine details in time-spatial structure of diffuse and discrete auroras. The gradient filtered keogram, where the arrows show the moments of brightening, makes it possible to enter into details of auroral arc dynamics. One can see from the filtered keogram (on the second plate of Fig. 5) that it is difficult to identify any distortion poleward of the brightening arc, which can be treated as the arc activation. The small magnetic oscillations in the Pi1-Pi2 frequency range constantly 

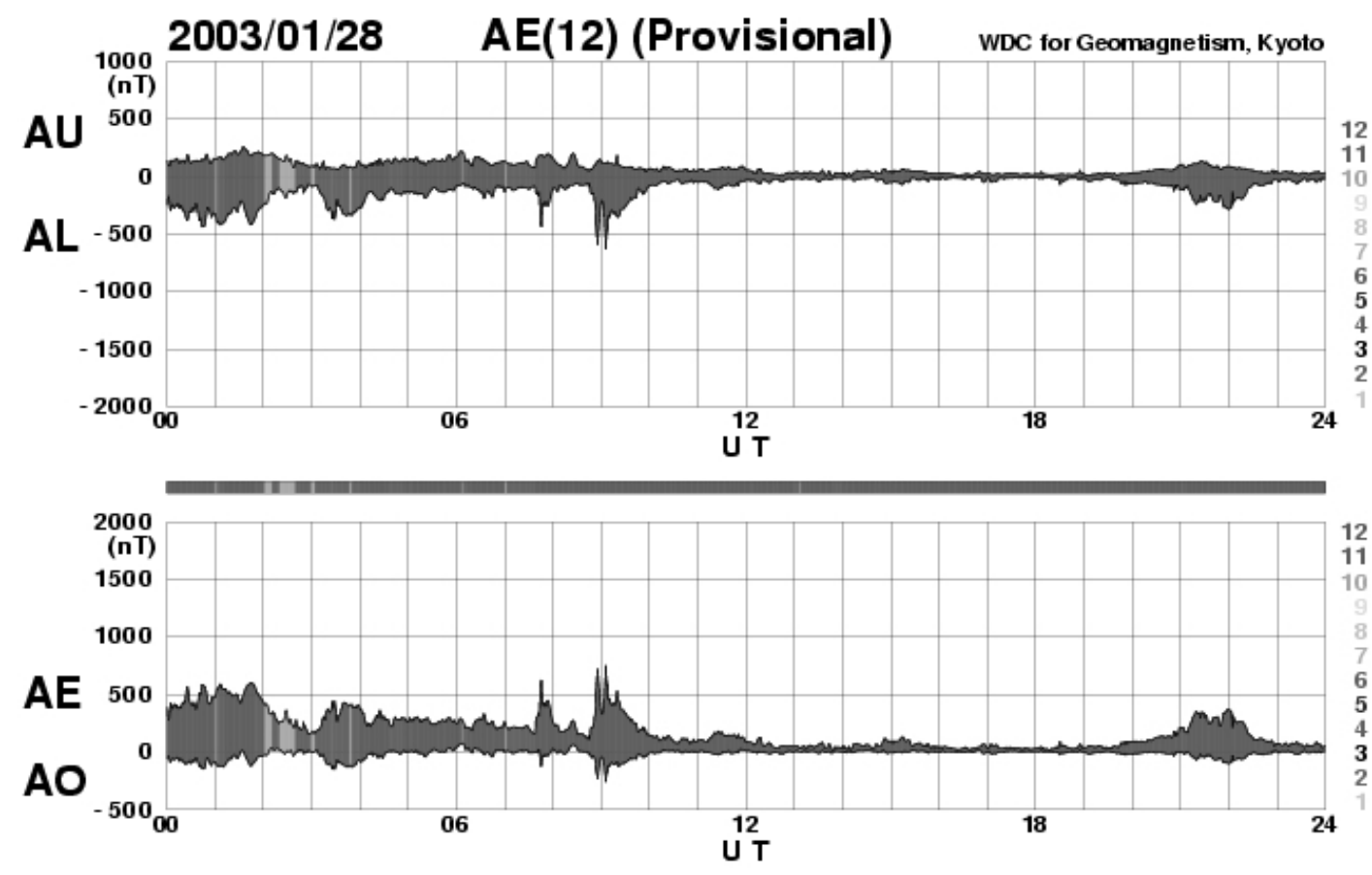

[C reated at 2008-08-02 06-24UT]

Fig. 1. Geomagnetic indexes for the event 28 January 2003.

occurred near the noise level, but amplitude of these oscillations increased essentially only $\sim 1 \mathrm{~min}$ after the brightening beginning. The later finding supports the conclusions of Liou et al. (1999), Mende et al. (2007), Angelopoulos et al. (2008) about the existence of definite time delay between the beginning of brightening and the appearance of the magnetic field disturbance.

\section{Constrains on the theories describing the substorm expansion phase onset}

The existence of time delay $\sim 1$ min between the first auroral arc brightening and the start of the distortion of the geomagnetic field provides the real constrains to existing theories concerning the substorm expansion phase onset and bright auroral arc formation. Theories of current disruption and ballooning instability formation suggest development of the electromagnetic disturbances (see Lui, 2004). Therefore, it is difficult to explain the existence of the observed time delay between the brightening and start of magnetic disturbance.

Electron fluxes producing the first auroral arc brightening have the form of field-aligned electron beams (Mende et al., 2003; Dubyagin et al., 2003; Shiokawa et al., 2005). Beams intensities are larger than $10^{10}$ particles $/ \mathrm{cm}^{2} \mathrm{~s}$. The particle densities available in beams $\left(\sim 10-10^{2} \mathrm{~cm}^{-3}\right)$ cannot come from acceleration of plasma sheet electrons. Only comparatively dense electrons of ionospheric origin accelerated not very far from the Earth (at heights $\sim 10000 \mathrm{~km}$ ), can form the

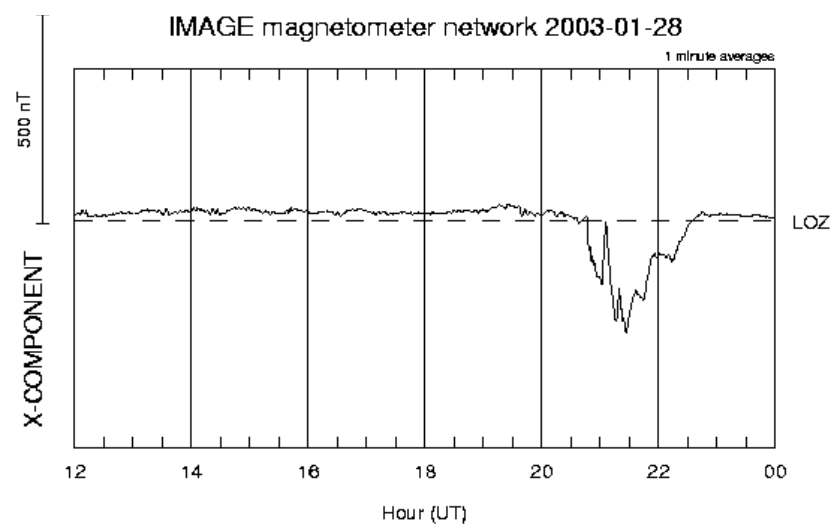

Fig. 2. X-component of the geomagnetic field at the Lovozero observatory.

observed electron beams. If electrons in the brightening arcs are accelerated by electric field of Alfvén waves, as it is commonly suggested (see Paschmann et al., 2002), the delay time between the visible aurorae, preceding the wave appearance, and magnetic field distortion must be much smaller than experimentally observed. Therefore, it is difficult to explain why the electron acceleration increase is not connected with the magnetic field distortion.

Discussed problems can be solved if we take into account that the downward acceleration of electrons is accompanied by the upward thin beams of the accelerated iononospheric 


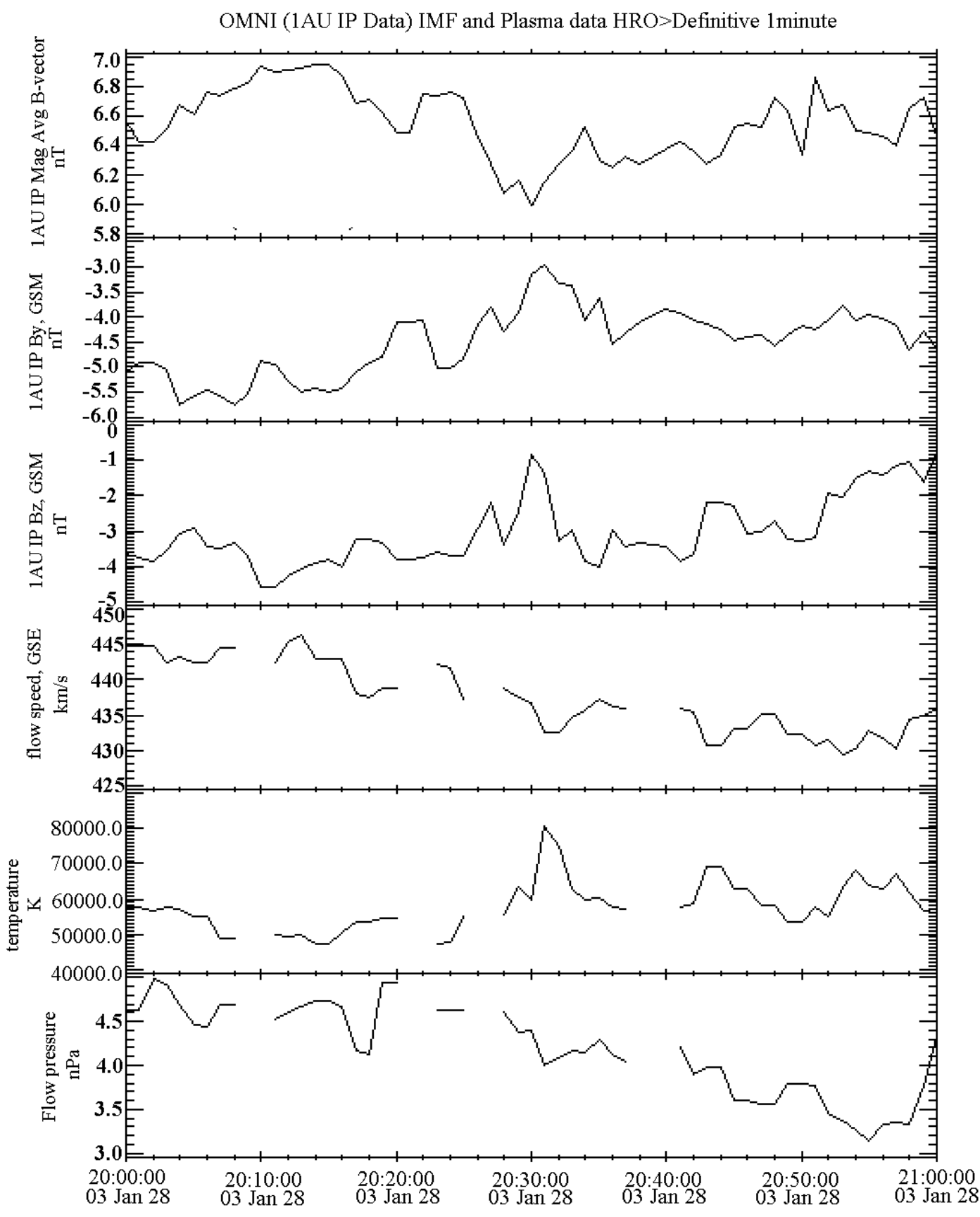

TIME RANGE $=2003 / 1 / 26(26)$ to $2003 / 1 / 26(26)$

Fig. 3. Solar wind parameters for the event 28 January 2003 taken from the OMNI database.

ions (Antonova, 2006). The beams of ionospheric ion will appear in the equatorial plane $\sim 1$ min after the arc brightening. They can be considered as one of the factors changing the stability of plasma distribution: very intense anisotropic ion beam will produce unstable plasma configuration. Different instabilities, leading to appearance of the intense electric and magnetic field fluctuations, can be developed. All these effects are traditionally examined in framework of the current disruption models (irregular geomagnetic micropul- sations, field line dipolarization). It is worthy to mention also that the very thin current sheets are observed at geocentric distances $\sim 10 R_{E}$ (see Sergeev et al., 1993; Yahnin et al., 2002; Petrukovich and Yahnin, 2006). Existing theories of the thin current sheet formation (see Kropotkin et al., 1997; Zelenyi et al., 2002, etc.) predict the sharp ion anisotropy inside the thin current sheet. Such anisotropy will appear due to ion beams from the ionosphere. 


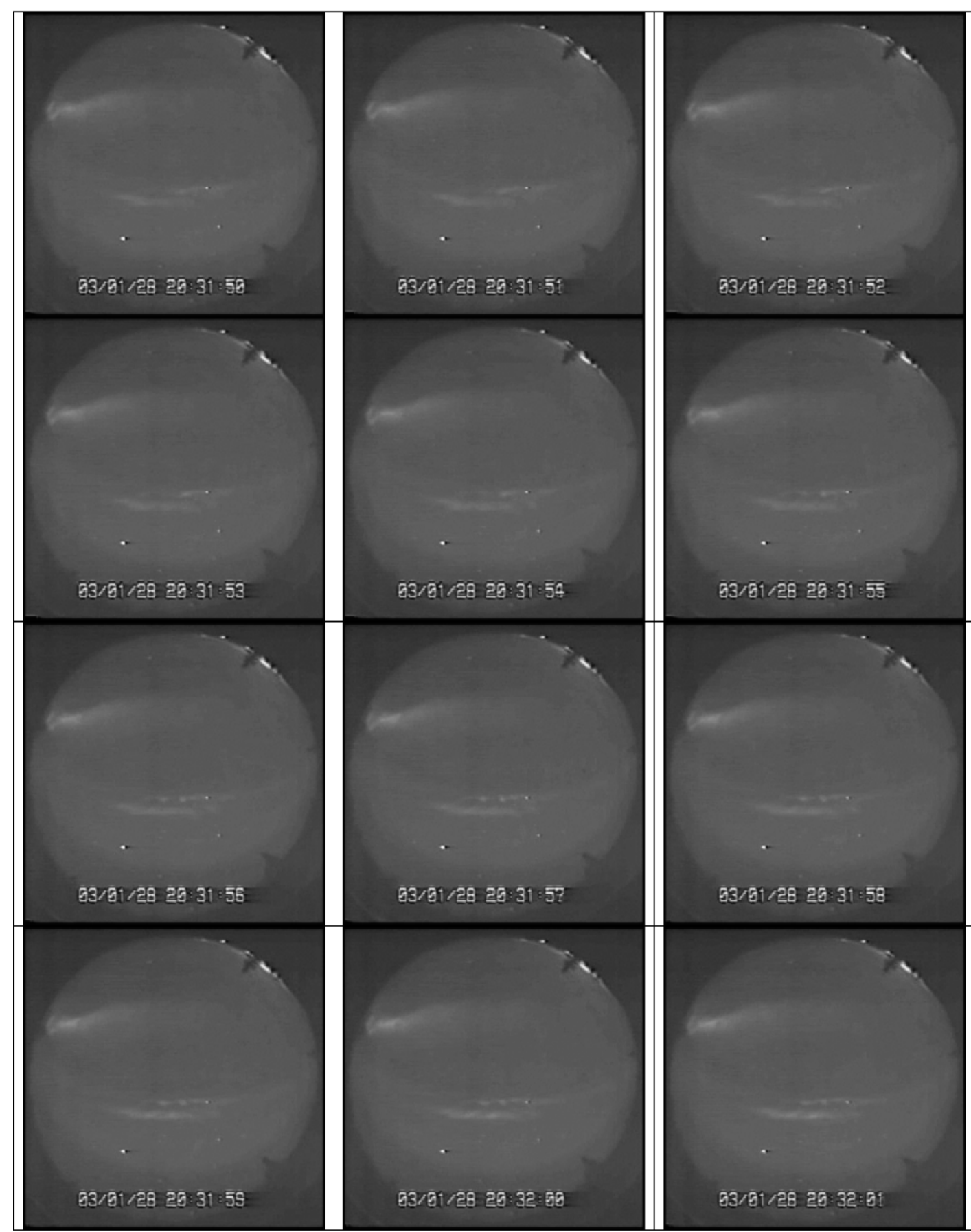

Fig. 4. Auroral imagers for the event 28 January 2003.

The discussed arguments point on process of the first auroral arc brightening as the main element for theoretical description of the substorm expansion phase onset. The possible scenario has been suggested by Antonova (1993), Stepanova et al. (2002). According to this scenario, the breakup originates on quasidipole magnetic field lines near the edge of the most equatorial structure of the inverted $\mathrm{V}$ type in region of the upward field-aligned current. When the pressure azimuthal gradient and the corresponding field aligned currents flowing out of the ionosphere exceed certain threshold values, the quasi-electrostatic instability develops and the plasma flow across the inverted V structure is formed. Such structures, frequently demonstrating the inverted U form, were named by Newell (2000) as large-scale 




Fig. 4. Continued.

electron acceleration events, but we shall hold on the traditional terminology. The quasistationary potential drops are typical of structures of inverted V type. When a cold dense ionospheric plasma gets into the region of the field-aligned potential drop, the powerful field-aligned plasma beams are formed at the boundary of inverted $\mathrm{V}$ structure, the electron beam being moved towards the ionosphere and the ion beam of the same intensity being moved towards the mag- netosphere. The powerful electron beam should be followed by occurrence of the thin bright discrete auroras. The maximal energy of electrons in the beam cannot exceed the fieldaligned potential drop in the inverted V structure. Results of satellite observations of the powerful field-aligned electron beams at the boundary of inverted $\mathrm{V}$ structure in time of the substorm onset (Mende et al., 2003; Dubyagin et al., 2003; Shiokava et al., 2005) are indicative of such scenario 




Fig. 4. Continued.

realization. The field-aligned current system formed at the boundary of inverted $\mathrm{V}$ structure should be very localized, with scale of $\sim$ brightening arc width. The magnetic field disturbance produced by such system can be measured only when crossing the brightening arc (see plot (a) of Fig. 3 in the paper of Mende et al., 2003).

\section{Conclusions and discussion}

To study features of the substorm expansion phase onset we have analyzed one of the most representative substorms of 60 events examined by Kornilov et al. (2008a, b). We deal with well isolated substorm, when the auroral arc brightening takes place at the zenith of Lovozero observatory. The breakups conditions were not so good for another events, but 
28.01.03 Lov. $20.00-21.00$
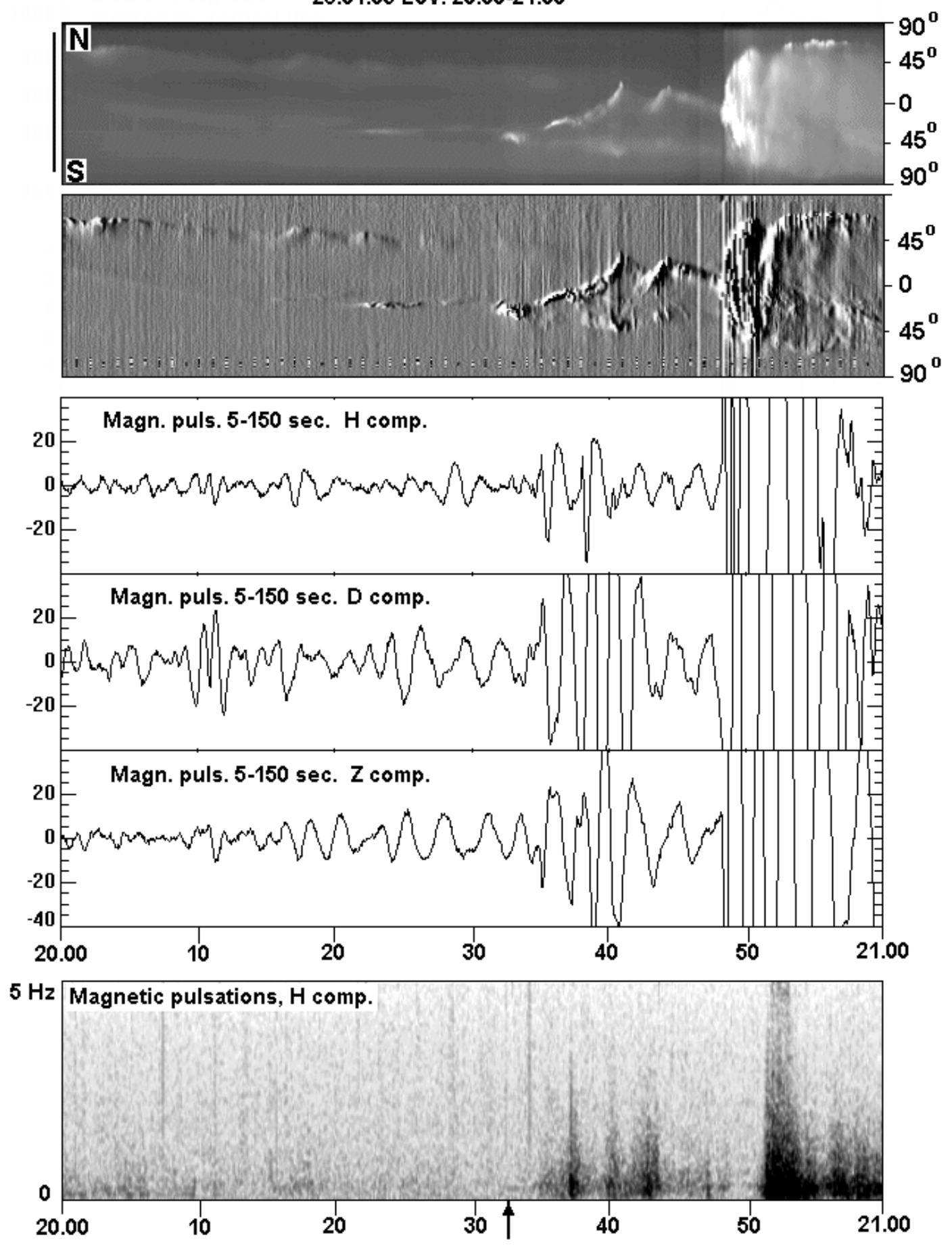

Fig. 5. Standard and filtered keograms of analyzed event and magnetometer data.

the analysis of auroral dynamics with resolution 25 frames per second made it possible to check early findings and to find some details providing the proper picture of auroral breakup. The minimal changes in the aurora morphology were observed before the arc brightening. Auroral arc is ordinary considered as a region of upward field-aligned current.
The availability of the stable arc implies the existence of the equilibrium magnetospheric configuration in that part of the equatorial plane where the arc is mapped.

Results of the study supports the existence of delay time between the first auroral arc brightening and start of the large magnetic fluctuations in the Pi1-Pi2 frequency range. The 
latter can point out on development of some kind of the quasi-electrostatic instability at moment of the first auroral arc brightening (see Antonova, 2006). Development of such electrostatic instability can precede the electromagnetic processes, which result in the dipolarization of magnetic field lines and injection of particles into the magnetosphere.

It is worthy to note also that results of TV observations demonstrate the formation of rayed auroral structure in process of the first auroral arc brightening. This feature, coinciding with the results of multiple visual breakup observations, means that development of the comparatively quick instability leads to the arc splitting on the rays. Such splitting is difficult to study using the all-sky observations. Since the ordinary observed rays have nearly cylindrical structure, it means that the scale of the disturbance related rayed structure is of the order of the bright arc thickness.

The formation of bright "hot spot" $\sim 15 \mathrm{~s}$ ahead of the classical brightening of the whole arc is another interesting results of the presented observations. The existence of such "hot spot" can be treated as a definite stage of the first auroral arc brightening, if it will be supported by the results of other observations. Location of the "hot spot" was practically unchanged during the analyzed period. This feature can indicate development of the very local instability during the first stage of arc brightening. The proper model for description of such events is required.

While using even the special methods of image filtering we could not find any signatures of the luminosity disturbance poleward of the arc during $\sim 1$ min before the arc brightening. The finding supports the results of Frank and Sigwarth (2000), Mende et al. (2007) (see also discussions of Lui, 2000; Lyons et al., 2000; Ohtani, 2004) and confirms the "inside-out" model. Our observations are incompatible with the scenario, in which substorm expansion phase onset arises as an immediate consequence of reconnection-driven fast flows or Alfvén wave from the middle tail. At the same time, it is necessary to mention that disturbances, produced by tail reconnection, can be very small, and the large increase of the sensitivity of the existing observations is required to make the final solution.

Acknowledgements. We thank Lovozero observatory staff carried out TV observations, Kyoto AE index service, NASA GSFC and CDAWeb. The work is supported by FONDECYT grant 1070131, RFBR grant 06-05-64374a.

Topical Editor R. Nakamura thanks O. Troshichev and another anonymous referee for their help in evaluating this paper.

\section{References}

Akasofu, S.-I.: The development of the auroral substorm, Planet. Space Sci., 12(4), 273-282, 1964.

Angelopoulos, V., Baumjohann, W., Kennel, C. F., Coroniti, F. V., Kivelson, M. G., Pellat, R., Walker, R. J., Liihr, H., and Paschmann, G.: Bursty bulk flows in the inner plasma sheet, J. Geophys. Res., 97(4), 4027-4039, 1992.
Angelopoulos, V., Mukai, T., and Kokubun, S.: Evidence for intermittency in Earth's plasma sheet and implications for selforganized criticality, Phys. Plasmas, 6(11), 4161-4168, 1999.

Angelopoulos, V., McFadden, J. P., Larson, D., Carlson, C. W., et al.: Tail reconnection triggering substorm onset, Science, 321(5891), 931-935, 2008.

Antonova, E. E.: The development of initial substorm expansion phase disturbance due to generation of localized electric fields in the region of maximum upward field-aligned current, Adv. Space Res., 13(4), 261-264, 1993.

Antonova, E. E.: Magnetostatic equilibrium and turbulent transport in Earth's magnetosphere: A review of experimental observation data and theoretical approach, Int. J. Geomag. Aeronomy, 3(2), 117-130, 2002.

Antonova, E. E.: Onset of Substorm Expansion Phase:Theory Predictions and Results of Experimental Observations, in: Proceedings of the 8th InternationalConference on Substorms (ICS-8), Banff, Canada, 1-6, 2006.

Baumjohann, W., Paschmann, G., and Lühr, H.: Characteristics of high-speed ion flows in the plasma sheet, J. Geophys. Res., 95(4), 3801-3809, 1990.

Borovsky, J. E., Elphic, R. C., Funsten, H. O., and Thomsen, M. F.: The Earth's plasma sheet as a laboratory for turbulence in high- $\beta$ MHD, J. Plasma Phys., 57(1), 1-34, 1997.

Borovsky, J. E. and Funsten, H. E.: MHD turbulence in the Earth's plasma sheet: Dynamics, dissipation and driving, J. Geophys. Res., 107(A7), 1284, doi:10.1029/2002JA009601, 2003.

Donovan, E., Mende, S., Jackel, B., Frey, H., et al.: The THEMIS all-sky imaging array-system design and initial results from the prototype imager, J. Atmos. Sol. Terr. Phys., 68(9), 1472-1487, 2006.

Dubyagin, S. V., Sergeev, V. A., Carlson, C. W., Marple, S. R., Pulkkinen, T. I., and Yahnin, A. G.: Evidence of nearEarth breakup location, Geophys. Res. Lett., 30(6), 1282, doi:10.1029/2002GL016569, 2003.

Frank, L. A. and Sigwarth, J. B.: Findings concerning the position of substorm onsets with auroral images from the Polar spacecraft, J. Geophys. Res., 105(A6), 12747-12761, 2000.

Kepko, L., Kivelson, M. G., McPherron, R. L., and Spence, H. E.: Relative timing of substorm onset phenomena, J. Geophys. Res., 109, A04203, doi:10.1029/2003JA010285, 2004.

Kornilov, I. A. and Kornilov, O. I.: Using image filtering method for the aurora TV data processing, Technique and methods of geophysical experiments, Edited in PGI, Apatity, 86-91, 2003.

Kornilov, I. A., Antonova, E. E., Kornilova, T. A., and Kornilov, O. I.: Fine structure of auroras during auroral breakup according to the ground based and satellite observations, Geomagn. Aeronomy, 48(1), 7-19, 2008.

Kornilova, T. A., Kornilov, I. A., and Kornilov, O. I.: Fine structure of breakup development inferred from satellite and ground-based observations, Ann. Geophys., 26, 1141-1148, 2008, http://www.ann-geophys.net/26/1141/2008/.

Kornilova, T. A., Kornilov, I. A., and Kornilov, O. I.: Wave precursors of breakup, in: Proceedings of the 7th International Conference on Substorms, edited by: Ganuskina, N. and Pulkkinen, T., Helsinki, 168-171, 2004.

Kropotkin, A. P., Malova, H. V., and Sitnov, M. I.: Self-consistent structure of a thin anisotropic current sheet, J. Geophys. Res., 102(A10), 22099-22032, 1997. 
Liang, J., Donovan, E. F., Liu, W. W., Jackel, B., Syrjäsuo, M., Mende, S. B., Frey, H. U., Angelopoulos, V., and Connors, M.: Intensification of preexisting auroral arc at substorm expansion phase onset: Wave-like disruption during the first tens of seconds, Geophys. Res. Lett., 35, L17S19, doi:10.1029/2008GL033666, 2008.

Liou, K., Meng, C.-I., Lui, A. T. Y., Newell, P. T., Brittnacher, M., Parks, G., Reeves, G. D., Anderson, R. R., and Yumoto, Y.: On relative timing in substorm onset signatures, J. Geophys. Res., 104(A10), 22807-22817, 1999.

Lui, A. T. Y.: Highlights on how to interpret auroral observation in terms of plasma sheet processes, in: Proceedings of 5th International Conference on Substorms, St. Petersburg, Russia, 16-20 May 2000, Eur. Space Agency Spec. Publ., ESA SP 443, 231234, 2000.

Lui, A. T. Y.: Potential plasma instabilities for substorm expansion onsets, Space Sci. Rev., 113(1), 127-206, 2004.

Lui, A. T. Y., Volwerk, M., Dunlop, M. W., Alexeev, I. V., et al.: Near-Earth substorm features from multiple satellite observations, J. Geophys. Res., 113, A07S26, doi:10.1029/2007JA012738, 2008.

Lyons, R. L.: Determination of relative timing of near Earth substorm onset and tail reconnection, in Proceedings of the 5th International conference on Substorms, St. Peterburg, Russia, 16-20 May 2000, Eur. Space Agence Spec. Publ., ESA SP-443, 255262, 2000.

Lyons, L. R., Voronkov, I. O., Donovan, E. F., and Zesta, E.: Relation of substorm breakup arc to other growth-phase auroral arcs, J. Geophys. Res., 107(A11), 1390, doi:10.1029/2002JA009317, 2002.

Mende, S. B., Carlson, C. W., Frey, H. U., Peticolas, L. M., and Østgaard, N.: FAST and IMAGE-FUV observations of a substorm onset, J. Geophys. Res., 108(A9), 1344, doi:10.1029/2002JA009787, 2003.

Mende, S. B., Angelopoulos, V., Frey, H. U., Harris, S., Donovan, E., Jackel, B., Syrjaesuo, M., Russell, C .T., and Mann, I.: Determination of substorm onset timing and location using the THEMIS ground based observatories, Geophys. Res. Lett., 34, L17108, doi:10.1029/2007GL030850, 2007.
Newell, P. T.: Reconsidering the inverted-V particle signature: Relative frequency of large-scale electron acceleration events, J. Geophys. Res., 105(A7), 15779-15794, 2000.

Ohtani, S.-I.: Flowbursts in the plasma sheet and auroral substorm onset: Observational constraints on connection between midtail and near-Earth substorm processes, Space Sci. Rev., 113(1), 7796, 2004.

Paschmann, G., Haaland, S., and Treumann, R.: Auroral plasma physics, Space Sci. Rev., 103(1-4), 1-485, 2002.

Petrukovich, A. A., Baumjohann, W., Nakamura, R., Schödel, R., and Mukai, T.: Are earthward bursty bulk flows convective or field-aligned?, J. Geophys. Res., 106(A10), 21211-21215, 2001.

Petrukovich, A. A. and Yahnin, A. G.: The substorm onset location controversy, Space Sci. Rev., 122, 81-87, doi:10.1007/s11214006-7022-8, 2006.

Sergeev, V. A. , Mitchell, D. G., Russell, C. T., and Williams, D. J.: Structure of the tail plasma/current sheet at $\sim 11 R_{E}$ in the course of a substorm and its changes, J. Geophys. Res., 98(A10), 17345-17365, 1993.

Sergeev, V. A., Liou, K., Meng, C.-I., Newell, P. T., Brittnacher, M., Parks, G., and Reeves, G. D.: Development of auroral streamers in association with impulsive injections to the inner magnetotail, Geophys. Res. Lett., 26(3), 417-420, 1999.

Shiokawa, K., Yago, K., Yumoto, K., Baishev, D. G., Solovyev, S. I., Rich, F. J., and Mende, S. B.: Ground and satellite observationsof substorm onset arcs, J. Geophys. Res., 110(A12), A12225, doi:10.1029/2005JA011281, 2005.

Stepanova, M. V., Antonova, E. E., Bosqued, J. M., Kovrazhkin, R. A., and Aubel, K. R.: Asymmetry of auroral electron precipitations and its relationship to the substorm expansion phase onset, J. Geophys. Res., 107(A7), 1134, doi:10.1029/2001JA003503, 2002.

Yahnin, A. G., Sergeev, V. A., Kubyshkina, M. V., Pulkkinen, T. I., Liou, K., Meng, C.-I., Angelopoulos, V., Borodkova, N. L., Mukai, T., and Kokubun, S.: Timing and location of phenomena during auroral breakup: A case study, Adv. Space Res., 3(7), 1775-177, 2002.

Zelenyi, L. M., Delcourt, D. C., Malova, H. V., and Sharma, A. S.: "Aging" of the magnetotail thin current sheets, Geophys. Res. Lett., 29(12), 1608, doi:10.1029/2001GL013789, 2002. 